\title{
OPTIMIZATION VS INNOVATION IN A CAE ENVIRONMENT
}

\author{
Towards a "Computer Aided Inventing” Environment
}

\author{
Noel Leon ${ }^{1}$, Jorge Gutierrez ${ }^{1}$, Oscar Martinez ${ }^{2}$, Carlos Castillo ${ }^{1}$ \\ ${ }^{1}$ Center for Product Innovation and Development; ${ }^{2}$ Department of Mechanical Engineering, \\ ITESM, Campus Monterrey, Ave. Eugenio Garza Sada \# 2501, Colonia Tecnológico, \\ Monterrey, CP64841, Monterrey, México
}

\begin{abstract}
At the kernel of TRIZ are the concepts of technical and physical contradictions and its "elimination" through inventive principles revealed by Altshuller". Altshuller used the contradiction as one of the ways of identifying analogy between two different inventive problems. Recently Mann recognized that the contradiction "elimination" means rather more an improvement of the scenario but leading to new contradictions in an endless chain. Diverse authors have been analyzing the role of contradiction in product development and innovation. In this paper, a product development approach is presented where product performance enhancement is first achieved through quantitative changes in parametric design (optimization) and later through paradigm shift (innovation). The approach is based on the concept of changing the design scenario to "eliminate" technical or physical contradictions, which avoid achieving higher performance goals. Based on these results, product innovation is presented as "optimization" not restricted to parametric variation but extended to "concept variation." The role of "concept variation" in product innovation and its similarity and relationships to parametric optimization is analyzed in this paper, based on identifying contradictions that may be overcome through "constrained concept variations."
\end{abstract}

Key words: Computer-Aided Inventing, Systematic Innovation, TRIZ, Product Development, Product Optimization.

\section{INTRODUCTION}

Although the philosophers had discovered the role of contradictions and conflicts in empirical knowledge and in its resolution by synthesis of new 
systems, this knowledge had not been applied to empirical solutions of technical or scientific problems until Altshuller ${ }^{1}$ used the contradiction as one of the ways of identifying analogy between two different inventive problems. At the kernel of TRIZ are the concepts of technical and physical contradictions and its "elimination" through inventive principles and other tools revealed by Altshuller.

In the 19th century, Hegel $^{2}$ deployed the dialectic method based on the concept of advancing contradictory arguments of thesis and antithesis and seeking the resolution by synthesis. Kant studied the contradictions in empirical knowledge leading to principles of reasoning. Marx studied the dialectic from the view point of contradictions as conflicts inherent in systems that give rise to the emergence of another more inclusive systems influenced by the quantitative development of the conflicts. These German philosophers recognize three basic laws of dialectics:

- The law of the negation of negation, which conveys the direction of development.

- The law of the mutual transformation of quantitative and qualitative changes, which demonstrates the mechanism of development.

- The law of unity and struggle of opposites, which demonstrates the source of development

It is also stated that of those three, the third law is the nucleus of dialectics and the first two laws may be considered as particular cases.

Recently $\mathrm{Mann}^{3}$ recognized that the contradiction "elimination" means rather more an improvement of the scenario but leading to new contradictions in an endless chain. This recognition resembles the first law of dialectics, negation of negation. 


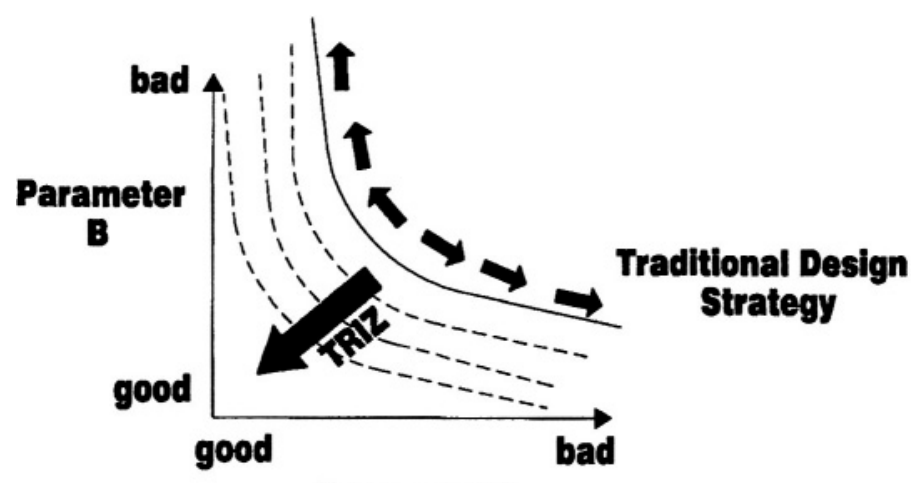

Parameter A

Figure 1. Traditional design vs. TRIZ

In the present paper the relationship between the second law, mutual transformation of quantitative and qualitative changes, and the third law, unity and struggle of opposites are judged against to the role of optimization and innovation in technical systems. It is known that commonly product performance enhancement is first achieved through quantitative changes in parametric design (optimization) and later, as the performance enhancement through optimization is exhausted, new searches are performed through paradigm shift or qualitative changes (innovation). Innovation allows then the removal of technical or physical contradictions, which were avoiding achieving enhanced performance goals (negation of negation). Darrell Mann represents this behavior diagrammatically in Fig. 1. Moving along the hyperboles means optimizing conflicting performance parameters (quantitative changes), while moving among the hyperboles means changing the function principle (qualitative changes).

The role of "concept variation" in product innovation and its similarity and relationships to extended parametric optimization is analyzed in this paper, based on identifying contradictions that may be overcome through "constrained concept variations."

This paper continues a series of papers about the research work that is being undertaken at the Center for Product Design and Innovation of the 
Monterrey Institute of Technology in Monterrey, Mexico, looking for the integration of different design tools and methodologies.

\section{OPTIMIZATION SYSTEMS BACKGROUND}

The evolution of Product Development tools has been characterized by different trends; the analysis of these trends offers useful hints for the prediction of next generation systems. The optimization of products and processes has been studied by many authors, especially since the widespread of computers as an aid for looking for "optimal" combination of product or process parameters ${ }^{4}$.

Especially the introduction of new techniques for Design of Experiments (DOE) in product or process improvement allowed reducing the number of experiments needed to identify the influence of different parameters in the performance objectives ${ }^{5}$. DOE also facilitated obtaining empirical mathematical models of the products and/or processes leading to the application of multi-objective optimization methods ${ }^{6}$. Furthermore, evolutionary and genetic algorithms ${ }^{7}$ in engineering optimization have contributed to the achievement of higher performance goals with multi objective optimization. Nevertheless, these techniques have been restricted to the search of product or process performance enhancement through the variation of numerical product or process parameters.

\subsection{Parametric optimization}

Parametric optimization is perhaps the most effective approach for many industrial solutions, as commonly parametric changes in products and process are easier to achieve and to implement than innovative concepts, where shape, topology, or physical principles are changed. However, parametric optimization alone could lead to stagnation in product or process development as compromise is inherent in parametric optimization, especially when multiple optimization objectives are targeted.

Multi objective optimization requires that "priorities" be defined among conflicting performance objectives, therefore leading to compromises in conflicting goals. The conflicting performance goals appear in any product or process development process avoiding achieving Anther enhancements through parametric multi objective optimization. 


\subsection{Shape and Topological Optimization}

When an absolute optimum is achieved through parametric optimization methods, the only way of achieving further performance enhancements is through innovative changes as shape or topological variations or as changing the physical functional principles. These changes often lead to better performance by overcoming the conflicting parameters. This is known as the "elimination" of the technical contradictions. However, achieving such changes requires commonly the inventive capabilities of designers and engineers.

The rapid development of the finite element method in recent years has also conduced to the introduction of the concepts of shape and topological optimization in engineering design in simulation software, which allow reducing the shape variation and topology variation to parametric changes in the product model while simulating its performance. Especially interesting are the trends of evolutionary algorithms to aerodynamic design optimization, in particular to turbine blade optimization using computational fluid dynamics packages. In this case, shape variations are achieved by fitting a spline to a target structure ${ }^{8}$. This approach is a special case as it actually reduces shape optimization to a parametric optimization of spline's parameters describing the airfoil section. A similar case study is performed by Obayashi, et. al. ${ }^{9}$ applying direct numerical optimization methods by coupling aerodynamic analysis methods with numerical optimization algorithms. They used multi objective genetic algorithms to minimize (or maximize) a given aerodynamic objective function by iterating directly on the geometry. In this case, aerodynamic design of a compressor blade shape is described by B-spline polygons from the leading edge to the trailing edge of the airfoil.

Another example comprise a numerical study of the thermal performance of an impingement heat sink - fin shape optimization ${ }^{10}$ varying the heat sink's shape. In this case, fin shapes were all parallel plate fins, with material removed from the region near the center of the heat sink.

An interesting case studying mechanisms performance by applying a systematic synthesis formulation is carried out by Sridhar et. al. ${ }^{11}$. They design compliant transmissions in micro electromechanical systems starting with desired force-displacement characteristics along specified directions and culminating in an "optimized design." In these cases, functional design that generates the desired output motion when subjected to prescribed input forces is searched by topological synthesis. Once a feasible topology is established, quantitative performance constraints can be imposed during the next stage in which size and shape optimization are performed using the energy formulation. 
A case study where parametric vs. shape, optimization was used to further enhance the performance; leading to an innovative evolution of the product is reported by Leon and Martinez ${ }^{12,13,14}$. A railroad brake beam was subject of improvement looking for reducing manufacturing costs as also structural weight and stress. It is easily recognized that these objective parameters conflict among each other. First, a parametric optimization of the existing brake beam design was developed by means of FEM analysis and optimization techniques. After that further improvement were achieved by changing the sectional shape of some brake beam components and performing a new parametric optimization procedure afterwards.

Heuristic, knowledge-based algorithms (e.g., expert systems) have been applied for searching the design space when shape and/or topology are "variables" of the product or process design. However, such expert systems have a very limited scope. Expert systems commonly require capturing expert knowledge before its introduction into software packages at a commonly very high cost, which not always pays for the performance enhancement achievable through them.

\section{INNOVATION AS CONCEPT OPTIMIZATION FOR COMPUTER AIDED INVENTING}

Based on former analysis, it may be stated that product innovation may also be implicit as "optimization not restricted to parametric variation" but extended to "constrained concept variation." As has been shown in several case studies, an extended parametric optimization is achieved by adding shape and topology as possible search directions. This extended optimization has been achieved by reducing the shape variation to a parametric variation of shapes represented by spline curves or by eliminating finite elements from a meshed structure ${ }^{15}$ to reduce it to a new shape or by considering predefined alternative shapes.

Extended shape generators in tree-structured CAD systems are under development ${ }^{16,17,18}$. These are able to produce variations of 3D-CAD shapes, which allow an "automatic" control of the shape variation not only when shapes are represented by parametric curves but also when represented as 3D shapes in 3D parametric CAD packages This symbolize a further step toward adding "concept variation" to optimization procedures.

The main problem for computer aided inventing algorithms resides in the fact that the possible concept variations of any product or process are infinite even inside of constrained spaces.

The computer aided optimization concept has to be based on techniques that reduce the search space by "sensing" the effect of variations of a 
reduced number of parameters involved. This means that an inherent contradiction is present at the widening of the search space to non parametric variations: the universe of possible solutions increases enormously to the extent that no computer aided methods are available for thoroughly searching the existing possibilities.

This inherent contradiction in computer aided inventing concept may be expressed as follows: the universe of possible variations should be widened as to not be constrained to only the parameters of the object's original functional principle but should be constrained as to reduce the search space to be affordable to existing optimization methods ${ }^{19}$.

This idea is inherent in the Algorithm for Solving Inventive Problems (ARIZ) proposed by Altshuller, as it is intended to guide inventors in the main direction for solving inventive problems without useless random search. Some "inventive principles" disclosed by Altshuller are of geometric nature and therefore they may be implemented to be performed in a CAD/CAE system when modeling or analyzing parts.

Other inventive principles are of rather topological nature and therefore may be implemented in CAD systems' assembly modules.

In other cases, the principles are of mechanical or physical nature, which also involves the effect of time and other physical parameters as velocity, force, acceleration, temperature, etc. and may be implemented using multibody systems.

\section{CONCLUSIONS}

Further research work is necessary to implement the "automatic" variation of shape, topology, and physical principles involved in a product development process following the recommendations derived from the simulation of the product performance parameters in a CAD/CAE environment.

Continuing advancing towards computer aided inventing tools requires further formalization of the interpretation of the Altshuller inventive principles in a CAD/CAE environment. Shape generators, which allow automated variations of existing 3D-CAD shapes, will allow designers use "search algorithms" for "optimal shapes" that enhance product performance beyond the results achievable through pure parametric optimization.

As the patterns of product evolution are useful in selecting the directions of possible variations to the functional principles further research work is also required looking for the possible selection of alternative functional principles in a computer aided inventing environment. 
An extended version of the paper will be presented at the Topical Session Top 6 Computer Aided Inventing of the IFIP World Computer Congress 2004, with further details and some examples about the proposed concepts.

\section{REFERENCES}

1. Altshuller, G.S. Creativity as an exact science: the theory of the solution of inventive problems/New York: Gordon andBreach, 1995

2. Hegel, G. W. F., Hauptwerke. In sechs Bänden”. Band 6. Enzyklopädie der philosophischen Wissenschaften im Grundrisse (1830). Hamburg, Meiner, 1999.

3. Mann, D., Contradiction Chains, The TRIZ-Journal, January 2001, http://www.trizjournal.com/archives/2000/01/a/index. htm

4. Fox, R. L, Optimization methods for engineering design, Addison-Wesley series in mechanics and thermodynamics, Reading, Mass.: Addison-Wesley Pub. Co., 1971

5. Box, G. E, and Draper, N. R., Evolutionary operation; a statistical method for process improvement, New York, Wiley, 1969, ISBN 047109305X

6. Deb, K., Multi-Objective Optimization Using Evolutionary Algorithms, Chichester: John Wiley \& Sons (Sd), 2001, ISBN 0471873397

7. Gen, M., Genetic algorithms and engineering optimization, A Wiley-Interscience publication, New York: Wiley, 2000, ISBN 0471315311.

8. Olhofer, M., Yaochu, J., Sendhoff, B., Adaptive encoding for aerodynamic shape optimization using evolution strategies, Evolutionary Computation, 2001. Proceedings of the 2001 Congress on, Volume: 1, 2001 Page(s): 576 -583 vol. 1

9. Obayashi, S., Tsukahara, T.; Nakamura, T. , Multiobjective genetic algorithm applied to aerodynamic design of cascade airfoils, Industrial Electronics, IEEE Transactions on, Volume: 47 Issue: 1, Feb. 2000 Page(s): 211 -216

10. Amit S., Sammakia, B., Srihari, H., Ramakrishna, K., A numerical study of the thermal performance of an impingement heat sink - fin shape optimization, Thermal and Thermomechanical Phenomena in Electronic Systems, 2002. ITHERM 2002. The Eighth Intersociety Conference on, 2002, Pages: 298 -306

11. Sridhar K., Hetrick, J., et al., Tailoring Unconventional Actuators Using Compliant Transmissions: Design Methods and Applications, IEEE/ASME TRANSACTIONS ON MECHATRONICS, VOL. 4, NO. 4, DECEMBER 1999, Pages 396-408

12. Patrick N. K., et. Al, Interdigitation For Effective Design Space Exploration Using ISIGHT, Journal of Structural and Multidisciplinary Optimization

13. Martinez, O, Leon, N. et. Al,. Comparación entre optimización paramétrica e innovación conceptual para el desarrollo de una viga óptima de frenado de ferrocarril, Memories del Congreso de Investigación y Extensión del Sistema ITESM, 1998, January 1998,Pages 246-255, Vol. 1, Monterrey, Mexico.

14. Martinez, $\mathrm{O}$, Integración de metodologías de diseño innovative y de optimización paramétrica aplicadas en el diseño de una guía de frenado de ferrocarril, Master Degree Thesis, ITESM, 1999 (unpublished)

15. Treviño, R., Revisión de técnicas de optimización de diseño y aplicación optimización topológica a eje frontal Master Degree Thesis, ITESM, 2001

16. Leon, N., A proposal to integrate TRIZ into the Product Design Process, Proceedings of TRIZCON2002., Conference Proceedings Pages 24-1 to 24-11, The $4^{\text {th }}$ Annual Conference of the Altshuller Institute for TRIZ Studies, St. Louis, Missour, USA, April 30-May 2, 2002 
17. Leon, N., Product Optimization vs. Innovation, Steps Toward a "Comuter Aided Inventing Environment, Proceedings of TRIZCON200e., Conference Proceedings Pages 2-1 to 2-12, The Fifth Annual Conference of the Altshuller Institute for TRIZ Studies, March 16-18, 2993, Philadelphia, Pennsylvania, USA

18. Abate, V., Cascini, G., CAD for Conceptual Design: Forecasted Evolution, The TRIZ Journal (May 2003); http://triz-journal.com.

19. Cavallucci, D., Lutz, P., Kucharavy, D., Converging in problem formulation: A different path in design, Proceedings of the $14^{\text {th }}$ ASME International Conference on Design Theory and Methodology Integrated Systems Design, Montreal, Canada, Sep 29-Oct 2 (2002). 